\title{
Spectral-kinetic properties of $\mathrm{LaF}_{3}$ nanoparticles doped with $\mathrm{Ce}^{3+}$ and $\mathrm{Sm}^{3+}$ ions after microwave treatment and in core-shell structure
}

\author{
E. I. Madirov*, E. V. Lukinova, A. S. Nizamutdinov, M. S. Pudovkin, S. L. Korableva, V. V. Semashko \\ Kazan Federal University, Institute of Physics, 18, Kremlevskaja str., Kazan, 420008, Russia \\ *ed.madirov@gmail.com
}

PACS 81.07.Bc, 76.30.Kg

DOI 10.17586/2220-8054-2018-9-6-783-788

\begin{abstract}
Crystalline $\mathrm{LaF}_{3}: \mathrm{Sm}^{3+}$ and $\mathrm{LaF}_{3}: \mathrm{Ce}^{3+}$ nanoparticles were fabricated via a co-precipitation method. The obtained nanoparticles were $15-20$ $\mathrm{nm}$ and had good crystallinity. Spectral-kinetic properties of crystalline $\mathrm{LaF}_{3}$ nanoparticles activated with $5 \% \mathrm{Sm}^{3+}$ and $12 \% \mathrm{Ce}^{3+}$ ions were studied. Various duration of the microwave treatment as well as core-shell structure were studied as possible ways to control quenching in the nanoparticles. In case of the $\mathrm{LaF}_{3}: \mathrm{Sm}^{3+}$ nanoparticles, the additional microwave treatment increased the average luminescence lifetime by $6 \%$ and addition of the $\mathrm{LaF}_{3}$ shell increased it by $18 \%$. In case of the $\mathrm{LaF}_{3}: \mathrm{Ce}^{3+}$ sample, microwave treatment increased the average lifetime by up to $20 \%$. The observed effects of varying the synthetic conditions and composite core-shell structure on luminescence properties of nanoparticles provide a means to manage the energy loss in the nanoparticles due to the quenching factors.
\end{abstract}

Keywords: nanoparticle, rare-earth ions, fluoride, samarium, cerium.

Received: 20 October 2018

Revised: 19 November 2018

\section{Introduction}

Currently, nanoparticles are the center of attention of the research from completely different fields of science [1, 2]. However, due to the size of nanoparticles their properties can significantly differ from the bulk materials of the same compound. A wide variety of chemical elements are used to produce nanoparticles [3,4]. The fluoride materials stand out amongst others because of their wide energy gap and low phonon energy usually observed in their crystal lattices. $\mathrm{LaF}_{3}$ is an interesting example of a fluoride that has been used as a host crystal for lanthanidedoped phosphors. Rare-earth metals are often utilized as activators in fluoride nanoparticles. Having sharp spectral lines, high photochemical stability and long fluorescence decay times, they are convenient material for lightemitting devices. Thus, depending on the excitation and luminescence spectral ranges of action, nanoparticles have a significant potential as up-conversion materials, photosensitizers, etc.

Medicine is another major possibility to utilize the unique properties of nanoparticles [5-7]. Photodynamic therapy (PTD) is a developing method of cancer treatment which has some advantages over conventional methods of cancer treatment like radiotherapy and chemotherapy such as lower impact on healthy organs. However, because dyes used in the PDT require visible range light for excitation, currently it is only possible to apply PDT to surface cancers. However, it can be changed with the combination of PDT agents and scintillator nanoparticles that provide down-conversion from x-ray to visible range [8]. Nanoparticles that could be used in PDT should meet certain requirements such as low size (10s of $\mathrm{nm}$ ), low toxicity, stable chemical composition and high down-conversion efficiency [9]. The fluoride materials meet most of these requirements and finding the right synthetic conditions might possibly provide desired optical properties [5].

Thus, a detailed study of the processes in nanoparticles, especially research into the energy transfer and decay processes as well as the study of the quenching mechanisms is required. The ability to control the transfer rates from a donor to an acceptor can significantly broaden the possible applications of nanoparticles.

Some work has already been done to understand the energy transfer and quenching of the luminescence mechanisms in the $\mathrm{Sm}^{3+}$-doped fluoride nanoparticles. For example, the role of the core-shell structure has been partially studied in the work by Anees A. Ansari [10]. In this paper, the effect $\mathrm{LaF}_{3}$ or $\mathrm{LaF}_{3} @ \mathrm{SiO}_{2}$ shell has on the optical properties of the $\mathrm{LaF}_{3}: \mathrm{Sm}^{3+}$ nanoparticles was studied using excitation and emission spectra. It was noted that "a remarkable intensity enhancement is recorded in the spectrum of core/shell-NPs in respect to coreNPs" [10]. However, this approach has some drawbacks. An additional layer of the undoped material increases the distance between luminescent ions and photosensitizers on the surface, thus decreasing the possible nonradiative energy transfer between the two. In addition, Juhong Miao et al. also studied the effect that $\mathrm{Sm}^{3+}$ concentration $^{3+}$ has on the luminescent properties of the nanoparticles in the paper [11]. Luminescence excitation, emission spectra as well as luminescence decay kinetics were used to study the concentration effects. It was demonstrated that by 
changing the percentage of the $\mathrm{Sm}^{3+}$ ions, one could significantly alter both luminescence intensity and decay lifetime. The results show both luminescence intensity and luminescence decay time reach a maximum at a $\mathrm{Sm}^{3+}$ concentration of $\sim 5 \mathrm{~mol} . \%$. Further increasing the concentration of $\mathrm{Sm}^{3+}$ leads to major concentration quenching with a more than a 2-fold reduction of the luminescence intensity and decay time decreasing from $180 \mu$ s to $20 \mu \mathrm{s}$.

The nanoparticles doped with $\mathrm{Ce}^{3+}$ have also been studied to some extent. Pushpal Ghosh et al. studied the effect of ultrasonication and annealing on the optical properties of $\mathrm{Ce}^{3+}$-doped nanoparticles [12]. Xiaoqing Zhang et al. discussed the influence of the synthetic temperatures and stoichiometry of reactants on the shape of the nanoparticles and decay lifetimes of the $\mathrm{Ce}^{3+}$ ions in the fluoride nanoparticles in the work [9]. In addition to this, there are works aimed at implementation of $\mathrm{Ce}^{3+}$-doped nanoparticles with PDT agents $[8,14]$. Previously, it was shown that a nonradiative energy transfer between lanthanide - doped fluoride nanoparticles and photosensitizers is possible [8]. It was also demonstrated that the energy transfer from nanoparticles significantly enhances luminescence of the photosensitizers. To do so, the emission of photosensitizer conjugates and doped and undoped nanoparticles was compared under $254 \mathrm{~nm}$ excitation. The results showed that the luminescence intensity of the conjugates of photosensitizer and doped nanoparticles was $15-20 \%$ higher that the intensity of the undoped ones. In paper [14], the authors have shown that $\mathrm{LaF}_{3}: \mathrm{Ce}^{3+} / \mathrm{DMSO}$ nanoparticles can be utilized as an intracellular light source for photodynamic activation. Also there is data suggesting that adding these nanoparticles amplifies the effect of the Protoporphyrin IX.

In this paper, we report on attempt to study the following methods of luminescence characteristics manipulation of nanoparticles: the variation of synthesis conditions and composite structure.

\section{Experimental details}

\subsection{Sample preparation}

Crystalline $\mathrm{LaF}_{3}: \mathrm{Sm}^{3+}\left(C_{\mathrm{Sm}}=\right.$ at. $\left.5 \%\right)$ and $\mathrm{LaF}_{3}: \mathrm{Ce}^{3+}\left(C_{\mathrm{Ce}}=\right.$ at. $\left.12 \%\right)$ nanoparticles were fabricated via co-precipitation method described earlier [15-19] at neutral $\mathrm{pH}$. The $\mathrm{LaF}_{3}: \mathrm{Sm}^{3+}$ samples were used to study the effect of the hydrothermal treatment (60 minutes exposure in the microwave oven) and core-shell composite structure on the spectral-kinetic properties of the nanoparticles. To create undoped $\mathrm{LaF}_{3}$ shell, $\mathrm{LaF}_{3}: \mathrm{Sm}^{3+}$ nanoparticles were dispersed in distilled water by sonication. Then $1.2 \mathrm{mmol}_{\text {of }} \mathrm{NH}_{4} \mathrm{~F}$ was added into suspension and the solution was heated to $50{ }^{\circ} \mathrm{C}$. After stirring for $15 \mathrm{~min}$ the $0.4 \mathrm{mmol}$ of $\mathrm{La}\left(\mathrm{NO}_{3}\right)_{3}$ was introduced into the solutions. The prepared suspension was placed into the microwave oven for 60 minutes. According to previous work [10] this approach allows to obtain samples with an undoped shell over a doped core nanoparticle.

The $\mathrm{LaF}_{3}: \mathrm{Ce}^{3+}$ samples were used to study the effect of the duration of the hydrothermal treatment on the spectral-kinetic properties of the nanoparticles. Three samples were collected: the first one was not exposed to any additional microwave radiation, the second one was exposed for 30 minutes and the third one was exposed for 180 minutes.

After synthesis, every sample was washed with distillate water and separated from the suspension by centrifugation and dried at $60{ }^{\circ} \mathrm{C}$ for $12 \mathrm{~h}$.

\subsection{Sample characterisation}

The TEM images of the obtained nanoparticles are presented in Fig. 1. It can be seen that the nanoparticles are 15-20 nm in average and have elliptical shape. In Fig. 1(b,d), it is explicitly shown that nanoparticles have welldefined atomic layers with distance between them about $0.33 \mathrm{~nm}$ that proves that particles have high crystallinity. This result is in good agreement with previous research, where the observed d-spacing was $0.31 \mathrm{~nm}$ [10].

To determine optical properties of the obtained nanoparticles, photoluminescence emission spectra and decay kinetics were recorded. A StellarNet EPP2000 spectrometer was used to detect the emission spectra. Decay kinetics were recorded with a MDR-23 monochromator and a FEU-100 photomultiplier tube.

The $405 \mathrm{~nm}$ emission of the second harmonic of the LT-2211 Ti:Sapphire laser was used for the excitation of the $\mathrm{LaF}_{3}: \mathrm{Sm}^{3+}$ samples, whereas the $266 \mathrm{~nm}$ emission of the 4th harmonic of a YAG:Nd solid-state laser was used as an excitation for the $\mathrm{LaF}_{3}: \mathrm{Ce}^{3+}$ samples.

\section{Results and discussion}

The luminescence spectra and decay kinetics of all nanoparticles were recorded. Whereas the luminescence spectra were in line with the spectra of $\mathrm{Sm}^{3+}$ or $\mathrm{Ce}^{3+}$ ions in single crystals [20,21] respectively, the decay kinetics differed significantly, showing non-mono exponential behavior.

The normalized luminescence spectra of the studied $\mathrm{LaF}_{3}: \mathrm{Sm}^{3+}$ nanoparticles are presented in Fig. 2(a, b, c). These spectra contain well known lines of transitions from ${ }^{4} \mathrm{G}_{5 / 2}$ state to ${ }^{6} \mathrm{H}_{J}$ terms. It should be noted that 


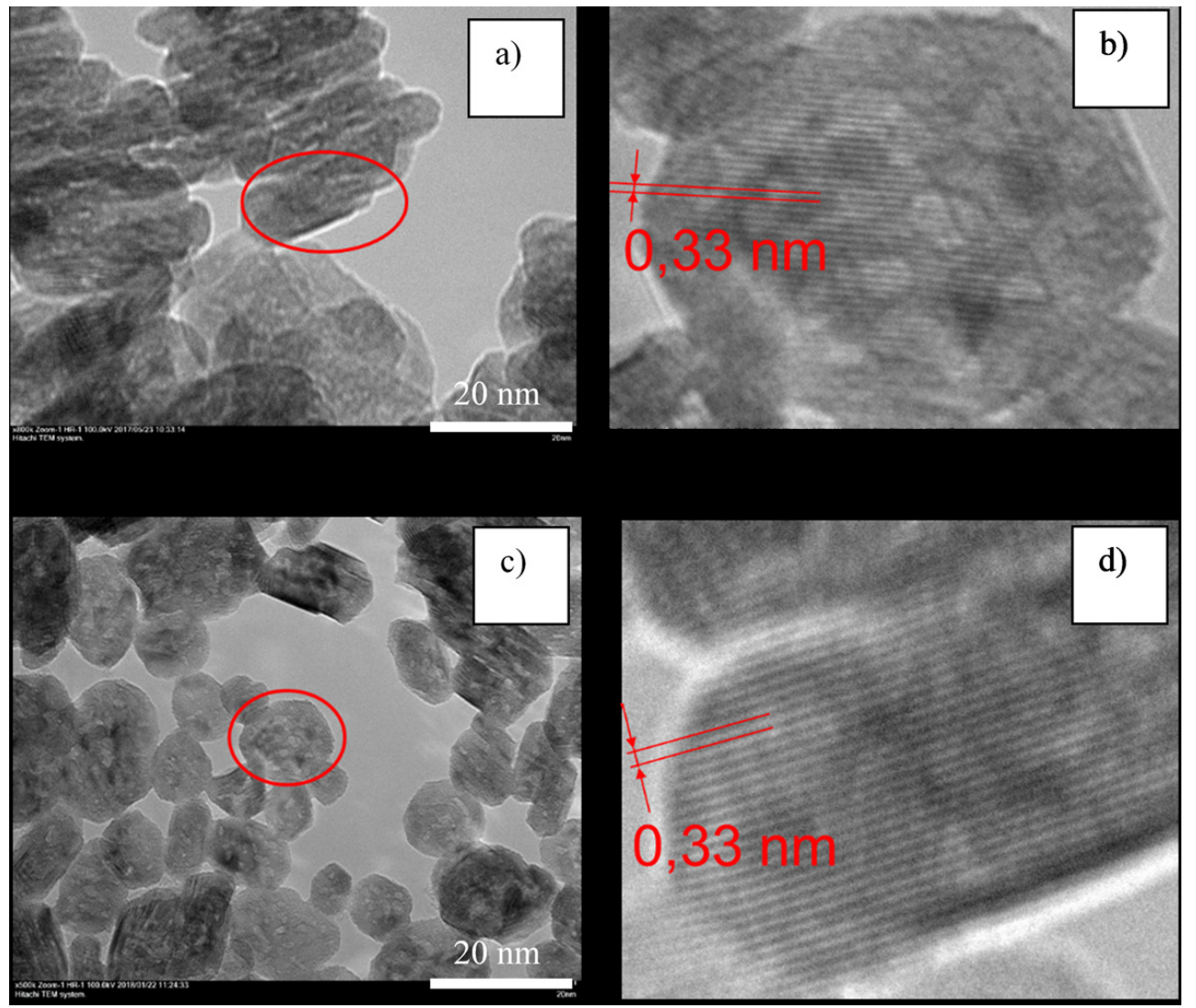

FIG. 1. TEM images of $\mathrm{LaF}_{3}: \mathrm{Sm}^{3+}(5 \%)$ nanoparticles (a), close-up of $\mathrm{LaF}_{3}: \mathrm{Sm}^{3+}(5 \%)$ nanoparticles (b), of $\mathrm{LaF}_{3}: \mathrm{Ce}^{3+}(5 \%)$ nanoparticles (c), close-up of $\mathrm{LaF}_{3}: \mathrm{Ce}^{3+}(5 \%)$ nanoparticles (d)

neither the microwave treatment nor the addition of the $\mathrm{LaF}_{3}$ shell alters the position of the peaks of the emission spectra, which proves that the local environment of the $\mathrm{Sm}^{3+}$ ions remains unaltered and there is no change of crystal structure.

The normalized luminescence spectra of the studied $\mathrm{LaF}_{3}: \mathrm{Ce}^{3+}$ nanoparticles are presented in Fig. 2(d, e, f). These spectra contain the well-known lines of $4 \mathrm{f}-5 \mathrm{~d}$ transitions in $\mathrm{Ce}^{3+}$ ions. As in the case of the $\mathrm{Sm}^{3+}-\mathrm{doped}^{3}$ nanoparticles, neither 30 minute nor 180 minute microwave treatment changes the position of the peaks of the emission spectra, thus proving that the local environment of the $\mathrm{Ce}^{3+}$ ions is identical in all samples and the crystal structure does not change.

Changes in the preparation method had a tangible effect on luminescence decay of the samples. The decay curves of all samples of $\mathrm{LaF}_{3}: \mathrm{Sm}^{3+}$ nanoparticles are presented in Fig. 3(a, b, c) and the decay curves of the $\mathrm{LaF}_{3}: \mathrm{Ce}^{3+}$ nanoparticles can be seen in Fig. 3(d, e, f). All samples have exhibited non-exponential decay, which is common for nanoparticles due to large surface to volume ratio and significant amount of surface perturbed sites [22] in case of $\mathrm{LaF}_{3}: \mathrm{Sm}^{3+}$, which empirically can be divided into fast and slow components. In case of $\mathrm{LaF}_{3}: \mathrm{Ce}^{3+}$ nanoparticles, it is believed that this feature is determined by regular sites and perturbed sites relaxation respectively [23].

To determine the slow and fast components of the luminescence decay time the bi-exponential fitting was used:

$$
y=y_{0}+A_{1} \exp \left(-t / \tau_{1}\right)+A_{2} \exp \left(-t / \tau_{2}\right) .
$$

In addition, we have determined the average lifetime of luminescence since bi-exponential fitting is only the assumption and could differ from real picture of the processes in nanoparticles. The average time was found using the following formula [24]:

$$
t_{a v g}=\frac{\int t I(t) d t}{\int I(t) d t} .
$$

The results are presented in the Table 1 . 

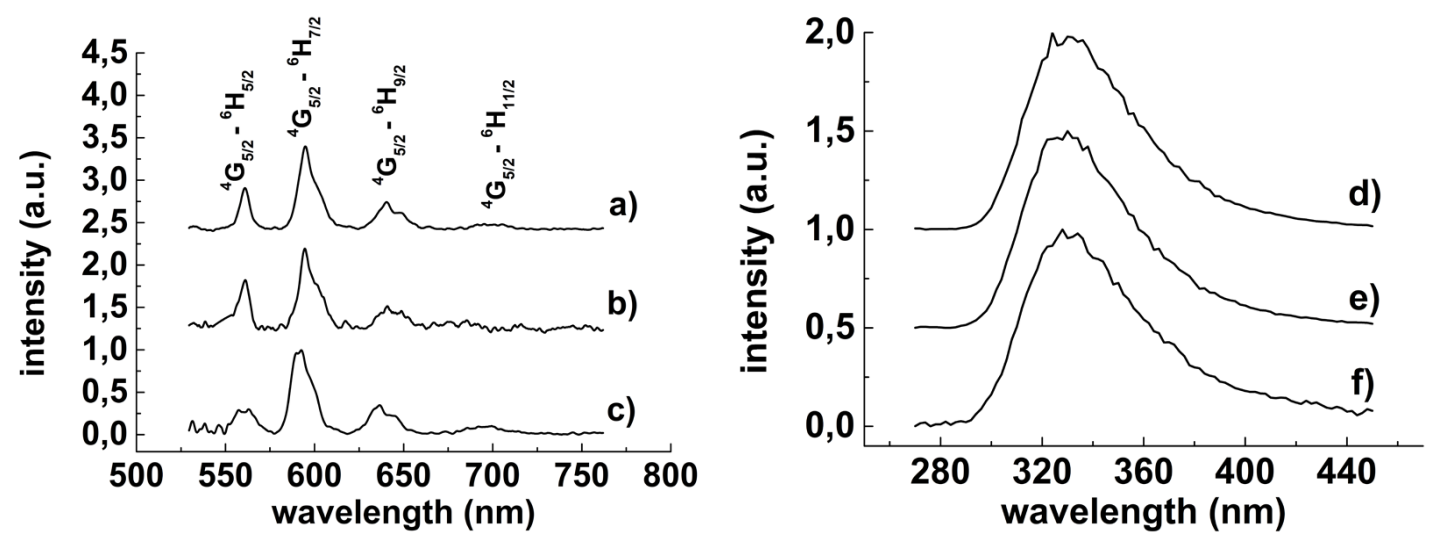

FIG. 2. PL emission spectra of the $\mathrm{LaF}_{3}: \mathrm{Sm}^{3+} 5 \%$ (a); $\mathrm{LaF}_{3}: \mathrm{Sm}^{3+} 5 \%$ with 60 min microwave exposure (b); $\mathrm{LaF}_{3}: \mathrm{Sm}^{3+} 5 \% @ \mathrm{LaF}_{3}$ core-shell nanoparticles under $405 \mathrm{~nm}$ excitation (c); $\mathrm{LaF}_{3}: \mathrm{Ce}^{3+}+12 \%$ (d); $\mathrm{LaF}_{3}: \mathrm{Ce}^{3+} 12 \%$ with 30 min microwave exposure; f) $\mathrm{LaF}_{3}: \mathrm{Ce}^{3+} 12 \%$ with $180 \mathrm{~min}$ microwave exposure nanoparticles under $266 \mathrm{~nm}$ excitation (e)
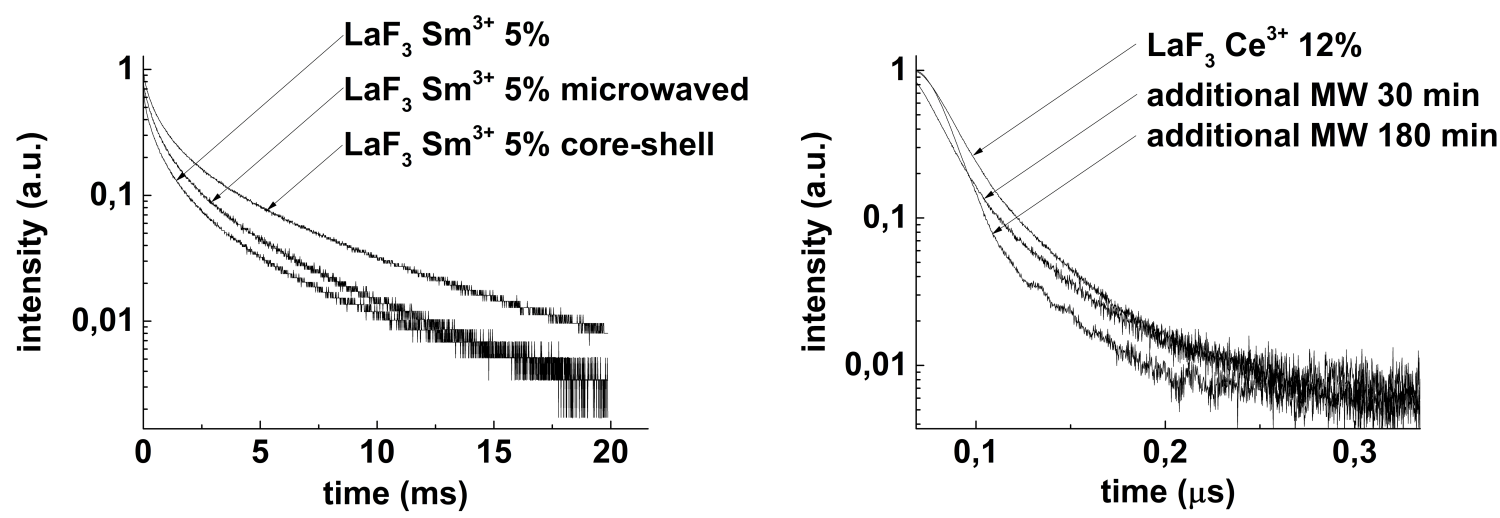

FIG. 3. PL decay kinetics of the $591 \mathrm{~nm}$ line of the $\mathrm{LaF}_{3}: \mathrm{Sm}^{3+}$ nanoparticles under $405 \mathrm{~nm}$ excitation (a); $330 \mathrm{~nm}$ line of the $\mathrm{LaF}_{3}: \mathrm{Ce}^{3+}$ nanoparticles under $266 \mathrm{~nm}$ excitation (b)

TABLE 1. Luminescence lifetimes of the $591 \mathrm{~nm}$ luminescence line of the $\mathrm{LaF}_{3}: \mathrm{Sm}^{3+}$ nanoparticles under $405 \mathrm{~nm}$ excitation

\begin{tabular}{|c|c|c|c|}
\hline & $\mathrm{LaF}_{3} \mathrm{Sm}^{3+} 5 \%$ & $\begin{array}{c}\mathrm{LaF}_{3} \mathrm{Sm}^{3+} 5 \% \\
\text { microwaved }\end{array}$ & $\begin{array}{c}\mathrm{LaF}_{3} \mathrm{Sm}^{3+} 5 \% \\
\text { core-shell }\end{array}$ \\
\hline Lifetime of the slow component $\tau_{1}$, ms & $3.3 \pm 0.1$ & $3.3 \pm 0.1$ & $4.3 \pm 0.1$ \\
\hline Lifetime of the fast component $\tau_{2}, \mathrm{~ms}$ & $0.4 \pm 0.1$ & $0.7 \pm 0.1$ & $0.8 \pm 0.1$ \\
\hline Average lifetime, ms & $1.7 \pm 0.5$ & $1.8 \pm 0.5$ & $2.0 \pm 0.5$ \\
\hline
\end{tabular}

The results in the Table 1 allow one to draw the following conclusions: 1) the existence of the un-doped $\mathrm{LaF}_{3}$ shell increases the decay times, apparently due to covering impurity sites at the surface thus eliminating surface quenching factors; 2) the microwave treatment of nanoparticles, on the contrary, has not introduced any significant effect in implemented conditions, which can speak for deficient fluorination or exposition during reaction.

Table 2 shows that both fast and slow components of the $\mathrm{Ce}^{3+}$ decay curves exhibit changes with synthesis procedure. The decay time of the slow component associated with the perturbed sites increases with the MW exposition time whereas lifetime of the fast component decreases though not that significantly. As well as this, the average lifetime shows general increase with the MW exposure time. The results of the approximations demonstrate that the perturbed sites are somehow more sensitive to the synthesis conditions. 
Spectral-kinetic properties of $\mathrm{LaF}_{3}$ nanoparticles doped with $\mathrm{Ce}^{3+}$ and $\mathrm{Sm}^{3+}$ ions ...

TABLE 2. Luminescence lifetimes of the $330 \mathrm{~nm}$ line of the $\mathrm{LaF}_{3}: \mathrm{Ce}^{3+}$ nanoparticles under $266 \mathrm{~nm}$ excitation

\begin{tabular}{|c|c|c|c|}
\hline & $\begin{array}{c}\mathrm{LaF}_{3} \mathrm{Ce}^{3+} 12 \% \\
\text { neutral pH }\end{array}$ & $\begin{array}{c}\text { additional } \\
\text { MW 30 min }\end{array}$ & $\begin{array}{c}\text { additional } \\
\text { MW 180 min }\end{array}$ \\
\hline Lifetime of the slowcomponent $\tau_{1}, \mathrm{~ns}$ & $36.6 \pm 0.5$ & $38.2 \pm 0.5$ & $43.1 \pm 0.5$ \\
\hline Lifetime of the fast component $\tau_{2}, \mathrm{~ns}$ & $9.8 \pm 0.5$ & $10.1 \pm 0.5$ & $7.9 \pm 0.5$ \\
\hline Average lifetime, ns & $29 \pm 1$ & $33 \pm 1$ & $35 \pm 1$ \\
\hline
\end{tabular}

\section{Conclusion}

Series of $\mathrm{LaF}_{3}: \mathrm{Sm}^{3+}$ and $\mathrm{LaF}_{3}: \mathrm{Ce}^{3+}$ crystalline nanoparticles were synthesized by a co-precipitation method. The size and morphology of the obtained nanoparticles were controlled using transmission electron microscopy. All of the particles were approximately $15-20 \mathrm{~nm}$ in size and had high crystallinity. The effects of the microwave treatment and additional undoped $\mathrm{LaF}_{3}$ shell on the luminescent features were studied using $\mathrm{LaF}_{3}: \mathrm{Sm}^{3+}$ nanoparticles. Modification of the $\mathrm{pH}$ and additional microwave treatment were carried out during the synthesis of the $\mathrm{LaF}_{3}: \mathrm{Ce}^{3+}$ nanoparticles. This also caused changes in the luminescence properties of the nanocrystals.

The spectral and kinetic properties of all of the nanoparticles were studied. Luminescence spectra as well as luminescence decay kinetics under $266 \mathrm{~nm}$ excitation in case of $\mathrm{LaF}_{3}: \mathrm{Ce}^{3+}$ nanoparticles and under $405 \mathrm{~nm}$ excitation in case of the $\mathrm{LaF}_{3}: \mathrm{Sm}^{3+}$ nanoparticles were recorded and decay times were estimated.

It was determined that the microwave exposure of the nanoparticles and addition of the $\mathrm{LaF}_{3}$ shell lessens the effect the quenching factors have on the luminescence decay time and increases the luminescence lifetime of the $\mathrm{LaF}_{3}$ nanoparticles doped with the $\mathrm{Ce}^{3+}$ or $\mathrm{Sm}^{3+}$ ions. The results of the experiments allowed us to obtain the following quantitative assessments: in case of the $\mathrm{LaF}_{3}$ nanoparticles doped with $\mathrm{Sm}^{3+}$ ions the additional microwave treatment increased the average lifetime by $6 \%$, whereas addition of the $\mathrm{LaF}_{3}$ shell increased it by almost $18 \%$; in case of the $\mathrm{LaF}_{3}$ nanoparticles doped with $\mathrm{Ce}^{3+}$ ions, the 30 minute microwave treatment increased the average lifetime by $13 \%$ and 180 minute treatment increased it by $20 \%$. Thus, we have proposed the approach to lessen the losses of excitation in $\mathrm{LaF}_{3}: \mathrm{Ce}^{3+}$ and $\mathrm{LaF}_{3}: \mathrm{Sm}^{3+}$ nanoparticles originated from quenching factors characteristic to nanosized crystals.

\section{Acknowledgements}

Studies were carried out in the frame of the state assignment in the sphere of scientific activities (Projects No. 3.1156.2017/4.6 and No. 3.5835.2017/6.7). Authors are grateful to specialists of Interdisciplinary Center of Analytical Microscopy of Kazan Federal University for microscopy studies.

\section{References}

[1] Kuznetsov S.V., Morozov O.A., et al. $\mathrm{Ca}_{1-x-y} \mathrm{Yb}_{x} \mathrm{Pr}_{y} \mathrm{~F}_{2+x+y}$ solid solution powders as a promising materials for crystalline silicon solar energetics. Nanosystems: Physics, Chemistry, Mathematic, 2018, 9 (2), P. 259-265.

[2] Fedorov P.P., et al. Nanofluorides. Journal of Fluorine Chemistry, 2011, 132 (12), P. 1012-1039.

[3] Shukla N., Saxena A.,et al. Magnetic silica nanoparticles for the removal of $\mathrm{Pb}^{2+}$ from water. Nanosystems: Physics, Chemistry, Mathematics, 2016, 7 (3), P. 488-491.

[4] Garanina A.S., et al. New superparamagnetic fluorescent $\mathrm{Fe} @ \mathrm{C}-\mathrm{C}_{5} \mathrm{ON}_{2} \mathrm{H}_{10}$-Alexa Fluor 647 nanoparticles for biological applications. Nanosystems: Physics, Chemistry, Mathematics, 2018, 9 (1), P. 120-122.

[5] Binnemans Koen. Lanthanide-based luminescent hybrid materials. Chemical reviews, 2009, 109 (9), P. $4283-4374$

[6] Zhang Q.Y., Huang X.Y. Recent progress in quantum cutting phosphors. Progress in materials Science, 2010,55 (5), P. $353-427$.

[7] Kozlov D.A., et al. The microstructure effect on the $\mathrm{Au} / \mathrm{TiO}_{2}$ and $\mathrm{Ag} / \mathrm{TiO}_{2}$ nanocomposites photocatalytic activity. Nanosystems: Physics, Chemistry, Mathematics, 2018, 9 (2), P. 266-278.

[8] Bekah, Devesh, et al. Synthesis and characterization of biologically stable, doped $\mathrm{LaF}_{3}$ nanoparticles co-conjugated to PEG and photosensitizers. Journal of Photochemistry and Photobiology A: Chemistry, 2016, 329, P. 26-34.

[9] Chatterjee, Dev Kumar, Li Shan Fong, Yong Zhang. Nanoparticles in photodynamic therapy: an emerging paradigm. Advanced drug delivery reviews, 2008, 60 (15), P. 1627-1637.

[10] Ansari A.A. Effect of Surface Functionalization on Structural and Optical Properties of Luminescent LaF 3 : Sm Nanoparticles. Journal of nanoscience and nanotechnology, 2018, 18 (2), P. 1043-1050.

[11] Miao Juhong, et al. Preparation, characterization and photoluminescence of $\mathrm{Sm}^{3+}$ doped NaGdF 4 nanoparticles. Journal of Alloys and Compounds, 2015, 636, P. 8-11.

[12] Ghosh Pushpal, Arik Kar, Amitava Patra. Structural Changes and Spectroscopic Properties of Ce ${ }^{3+}$-Ion-Doped Sodium Yttrium Fluoride Nanocrystals: Influences of Sonication and Temperature. The Journal of Physical Chemistry C, 2009, 114 (2), P. $715-722$. 
[13] Zhang Xiaoqing, et al. $\mathrm{NaGdF}_{4}: \mathrm{Ce}^{3+}$ and $(\mathrm{Ce}, \mathrm{Gd}) \mathrm{F}_{3}$ nanoparticles: Hydrothermal synthesis and luminescence properties. Materials Chemistry and Physics, 2010, 121 (1-2), P. 274-279.

[14] Zou Xiaoju, et al. X-ray-induced nanoparticle-based photodynamic therapy of cancer. Nanomedicine, 2014,9 (15), P. $2339-2351$.

[15] Wang Feng, et al. Facile synthesis of water-soluble $\mathrm{LaF}_{3}: \mathrm{Ln}^{3+}$ nanocrystals. Journal of Materials Chemistry, 2006,16 (11), P. $1031-1034$.

[16] Shao J., Wang Z., et al. Investigation on the preparation and luminescence emission of LaF $\mathrm{Lau}_{3}^{3+} @ \mathrm{LaF}_{3} / \mathrm{SiO}_{2}$ core-shell nanostructure. Journal of Solid State Chemistry, 2017, 249, P. 199-203.

[17] Pudovkin M.S., Morozov O.A., et al. Physical Background for Luminescence Thermometry Sensors Based on $\mathrm{Pr}^{3+} \mathrm{:LaF}_{3} \mathrm{Crystalline}$ Particles. Journal of Nanomaterials, 2017, 2017, 9 pp.

[18] Fedorov P.P., Mayakova M.N., et al. Synthesis of $\mathrm{CaF}_{2}-\mathrm{YF}_{3}$ nanopowders by co-precipitation from aqueos solutions. Nanosystems: Physics, Chemistry, Mathematic, 2017, 8 (4), P. 462-470.

[19] Alakshin E.M., Klochkov A.V., et al. Microwave-assisted hydrothermal synthesis and annealing of DyF 3 nanoparticles. Journal of Nanomaterials, 2016, 2016, 5 pp.

[20] Wang G.Q., et al. Polarized spectral properties of $\mathrm{Sm}^{3+}$ : LiYF 4 crystal. Journal of Luminescence, 2014,147, P. $23-26$.

[21] Elias L.R., Heaps Wm S., Yen W.M. Excitation of uv Fluorescence in $\mathrm{LaF}_{3}$ Doped with Trivalent Cerium and Praseodymium. Physical Review B, 1973, 8 (11), 4989.

[22] Runowski M., Lis S. Synthesis of lanthanide doped $\mathrm{CeF}^{3}: \mathrm{Gd}^{3+}, \mathrm{Sm}^{3+}$ nanoparticles, exhibiting altered luminescence after hydrothermal post-treatment. Journal of Alloys and Compounds, 2016, 661, P. 182-189.

[23] Cooper D.R., et al. Photoluminescence of cerium fluoride and cerium-doped lanthanum fluoride nanoparticles and investigation of energy transfer to photosensitizer molecules. Physical Chemistry Chemical Physics, 2014, 16 (24), P. 12441-12453.

[24] Rojas-Hernandez, Rocío Estefanía, Santos L.F., Almeida R.M. Tb ${ }^{3+} / \mathrm{Yb}^{3+}$ doped aluminosilicate phosphors for near infrared emission and efficient down-conversion. Journal of Luminescence, 2018, 197, P. 180-186. 